\title{
Estimating Volume of Shale in a Clastic Niger Delta Reservoir from Well Logs: A Comparative Study
}

\author{
Vianney M. Kamayou1* ${ }^{*}$, Chukwuemeka N. Ehirim², Sunday S. Ikiensikimama ${ }^{3}$ \\ ${ }^{1}$ Africa Centre of Excellence, Centre for Oilfield Chemicals Research (ACE-CEFOR), University of Port Harcourt, Choba, Port \\ Harcourt, Rivers State, Nigeria \\ ${ }^{2}$ Department of Physics, University of Port Harcourt, Choba, Port Harcourt, Rivers State, Nigeria \\ ${ }^{3}$ Department of Petroleum and Gas Engineering, University of Port Harcourt, Choba, Port Harcourt, Rivers State, Nigeria \\ Email: ^kamayouvianney@yahoo.fr, ehirimcn@yahoo.com, sunday.ikiensikimama@uniport.edu.ng
}

How to cite this paper: Kamayou, V.M., Ehirim, C.N. and Ikiensikimama, S.S. (2021) Estimating Volume of Shale in a Clastic Niger Delta Reservoir from Well Logs: A Comparative Study. International Journal of Geosciences, 12, 949-959.

https://doi.org/10.4236/ijg.2021.1210049

Received: July 20, 2021

Accepted: October 16, 2021

Published: October 19, 2021

Copyright $\odot 2021$ by author(s) and Scientific Research Publishing Inc. This work is licensed under the Creative Commons Attribution International License (CC BY 4.0).

http://creativecommons.org/licenses/by/4.0/ (c) (i) Open Access

\begin{abstract}
The volume of shale $\left(V_{\mathrm{sh}}\right)$ is a critical parameter in petrophysical analysis that enables the accurate estimation of other petrophysical parameters like effective porosity, saturation and Net-to-Gross. This is an important step in characterization of reservoirs as well as valuation of hydrocarbon potentials. GR (Gamma Ray), Neutron and Density as well as Potassium, Uranium and Thorium logs were adopted to estimate and analyze $V_{\text {sh }}$ for sand 4 reservoir interval across five wells using the empirical (GR-linear and non-linear) and Neutron-Density methods. Results show that $V_{\text {sh }}$ estimated by the different methods varied from 0.24 - 0.39 for the GR linear method (highest), $0.12-0.24$ for the Larionov method (intermediate), and $0.04-0.28$ for the Neutron-Density method (lowest). Although the Neutron-Density method gives the lowest values of volume of shale, this does not translate to the most accurate and reliable results. This may be attributed to the non-singularity in measurements and varying sensitivities of the well logs used in this method as well as the complexities of the wellbore condition. The GR non-linear (Larionov) method provides consistent and comparable volume of shale estimations with the neutron-density method than the linear GR method and consequently, the non-linear GR method is recommended for estimation of $V_{\mathrm{sh}}$ in the studied field.
\end{abstract}

\section{Keywords}

Volume of Shale, GRI, GR Method, Neutron-Density Method

\section{Introduction}

Well-logs are important downhole measurements in exploration geophysics. The 
interpretation of well logs is critical in estimating petrophysical (volume of shale $\left(V_{\text {sh }}\right)$, porosity $(\Phi)$ and saturation $\left(S_{w}\right)$ ) and geometrical (reservoir thickness and depth) properties of the reservoir in the vicinity of the borehole. Among the petrophysical properties, $V_{\mathrm{sh}}$ is the most basic and fundamental reservoir property that defines the quantity of shale present in hydrocarbon reservoirs. It is vital in the accurate estimation of other petrophysical properties such as effective porosity, Net to Gross, permeability and water saturation which are essential for determining reservoir quality, hydrocarbon potential and realistic calculation of hydrocarbon reserves [1].

There exist different methods of estimating $V_{\text {sh }}$ of a reservoir from well logs, which has been extensively discussed in literature [2] [3] [4] [5]. These are the GR, neutron-density, sonic, nuclear magnetic resonance (NMR), neural nets and machine learning methods. The GR and Neutron-Density methods will be considered in the present study. The empirical (linear and non-linear) method is the most frequently used $V_{\text {sh }}$ estimators based on the calculation of Gamma-Ray Index (GRI) from GR log [6]. However, these methods are generally affected by the type and distribution of shale and minimum trace of radioactive materials in the reservoir matrix, which may lead to an overestimation of $V_{\mathrm{sh}}$ in the studied reservoir interval [7] [8].

Furthermore, the neutron-density method is less influenced by the natural radioactivity of rocks and gives a more accurate estimation of $V_{\mathrm{sh}}$ in the absence of core data [2]. The major drawback of the neutron-density method lies on its dependency on the gas content of the formation [9]. The gas content of the formation affects the neutron-density log response, which could lead to inaccurate $V_{\text {sh }}$ estimation. The accuracy of any of the methods in $V_{\text {sh }}$ estimation depends on the quality of the logs and geological characteristics of the formation.

Our study area is located in the Central Swamp of Niger Delta Basin, Nigeria (Figure 1). The Benue Trough which is a bigger tectonic structure encompasses

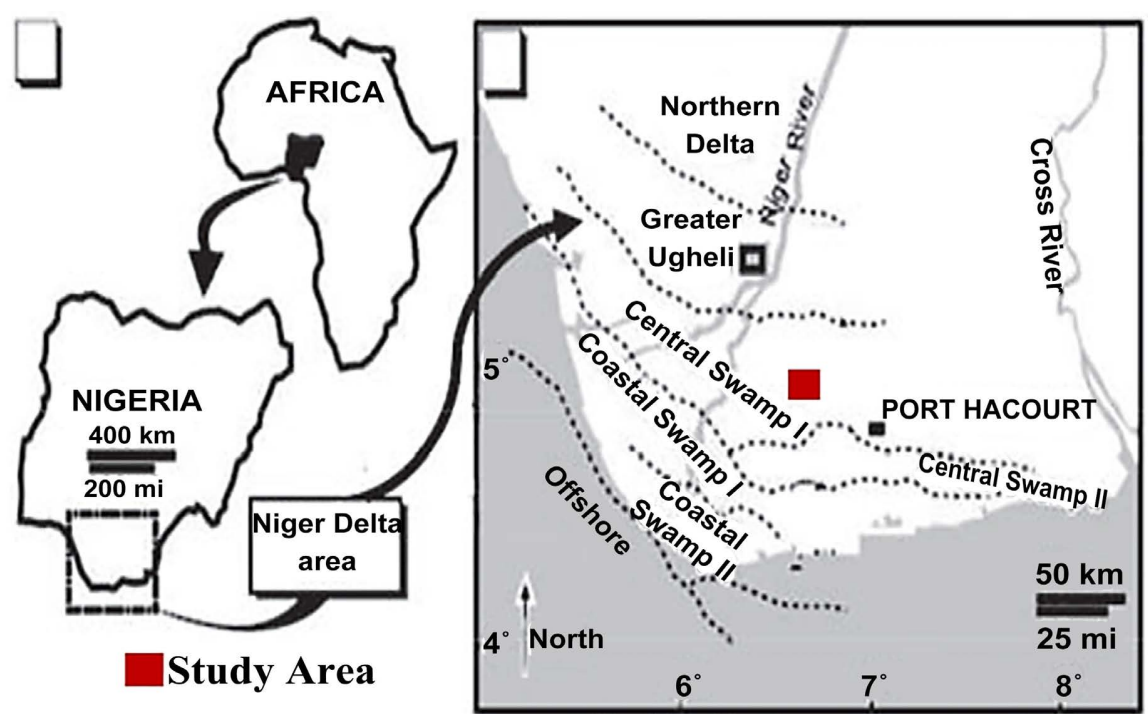

Figure 1. Location map of the study area [12]. 
the Niger Delta Basin in its South Westernmost part, while the Cameroon Volcanic Line and the transform passive continental margin bound the other side of the basin [10]. The basin is hydrocarbon bearing and characterized by clastic sedimentary deposits in overlapping but separate depobelts that eventually coalesced to form the present Niger delta sedimentary basin [11].

In well log analysis, the integration of various well logs helps in discriminating litho-fluid components and estimating reservoir properties. One well log type alone is the most unsuitable for petrophysical analysis and may give undesirable results in the estimation of reservoir properties. Therefore, the goal of this study specifically, is to estimate $V_{\text {sh }}$ of a clastic reservoir by integrating well logs and different computational strategies to deduce the best $V_{\text {sh }}$ estimator that could be used for robust petrophysical evaluation in the Niger Delta field.

\section{Geology of the Study Area}

The Niger Delta consists of clastic sediments deposited from the late Eocene to the Tertiary in the basin. It is characterised by three (3) litho-stratigraphic formations from earliest to latest as follows:

- The Akata Formation: mostly of marine origin and the major source rock.

- The Agbada Formation: characterised by shales and sands, hydrocarbon bearing and reservoir rock.

- The Benin Formation: characterised by sands and non-hydrocarbon bearing (Figure 2(a)).

The Akata-Agbada Formations form the major petroleum system in the basin with the major finds located in the upper Eocene Agbada Formation. These

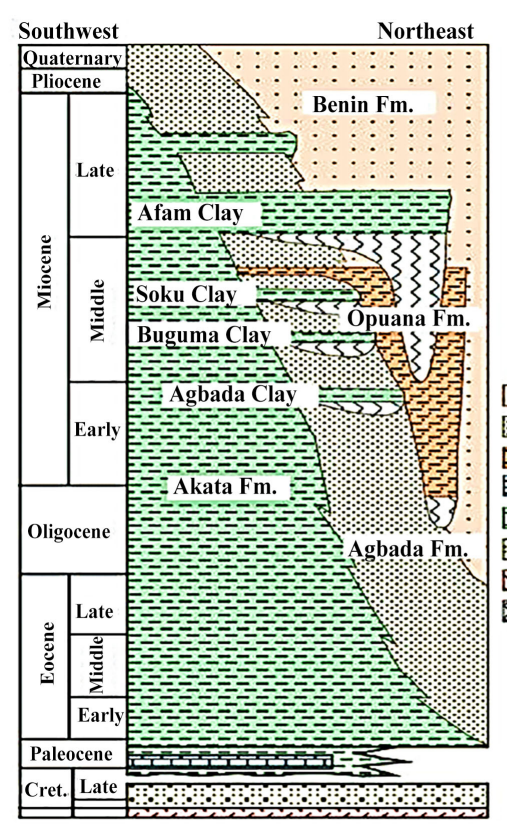

(a)

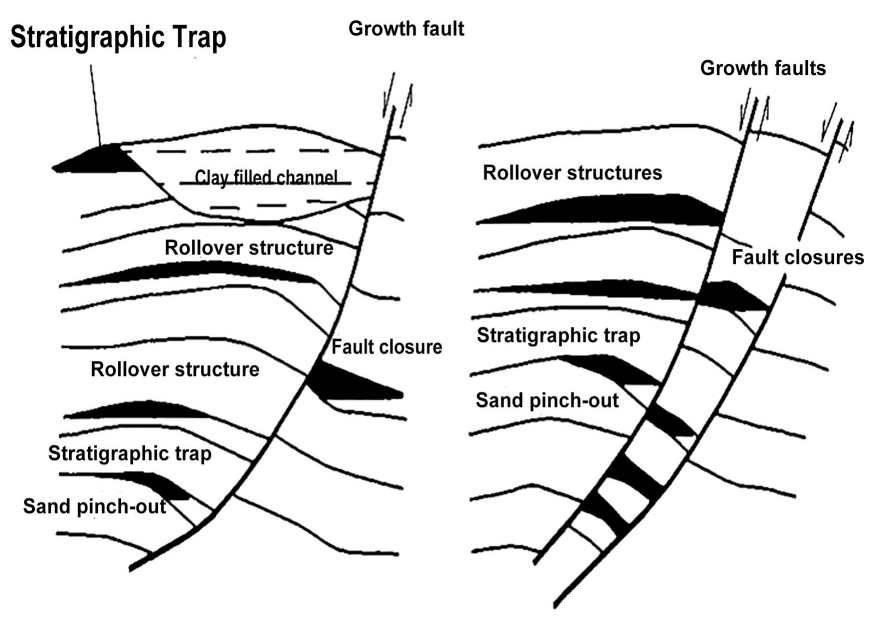

HYDROCARBON TRAP

MAIN BOUNDARY FAULT

(b)

Figure 2. (a) Lithostratigraphic map of the Niger Delta (b) Structural framework of the Niger Delta [11] [12]. 
formations are characterised by syn/post-sedimentary structural styles such as rollover anticlines, hanging-walls, foot-walls, back to back structures that affect hydrocarbons' migration and trapping in the basin (Figure 2(b)).

\section{Materials and Methods}

Six wells (V1 to V6) located in VIA field and with suit of logs namely Gamma Ray, Sonic, Calliper, Resistivity, Density, Neutron, Potassium, Thorium and Uranium logs were used in the present study (Figure 3 and Table 1). TECHLOG Software and Microsoft Excel worksheet were used for data analysis.

A thorough QA/QC as well as petrophysical evaluation was carried out on the logs. The petrophysical evaluation consists of identifying and mapping potential reservoir sands by discriminating between lithologies that is, shale from sandstone using GR log; discriminating hydrocarbon from non-hydrocarbon sandstones and differentiating gas and oil from brine sands using resistivity and combinations of neutron-density logs, respectively [13]. Furthermore, the mapped reservoir intervals were correlated across wells for purposes of continuity and structural controls.

Table 1. Available log suites in each well.

\begin{tabular}{ccccccccccc}
\hline Well Name & CALI & DT & GR & ILD & NPHI & RHOB & SP & POTA & THOR & URAN \\
\hline V1 & Y & Y & Y & Y & Y & Y & Y & N & N & N \\
V2 & Y & Y & Y & Y & Y & Y & Y & N & N & N \\
V3 & Y & N & Y & Y & Y & Y & Y & N & N & N \\
V4 & Y & N & Y & Y & Y & Y & Y & N & N & N \\
V5 & Y & Y & Y & Y & Y & Y & Y & Y & Y & Y \\
V6 & Y & Y & Y & Y & Y & Y & N & N & N & N \\
\hline
\end{tabular}

Y: Yes; N: No.

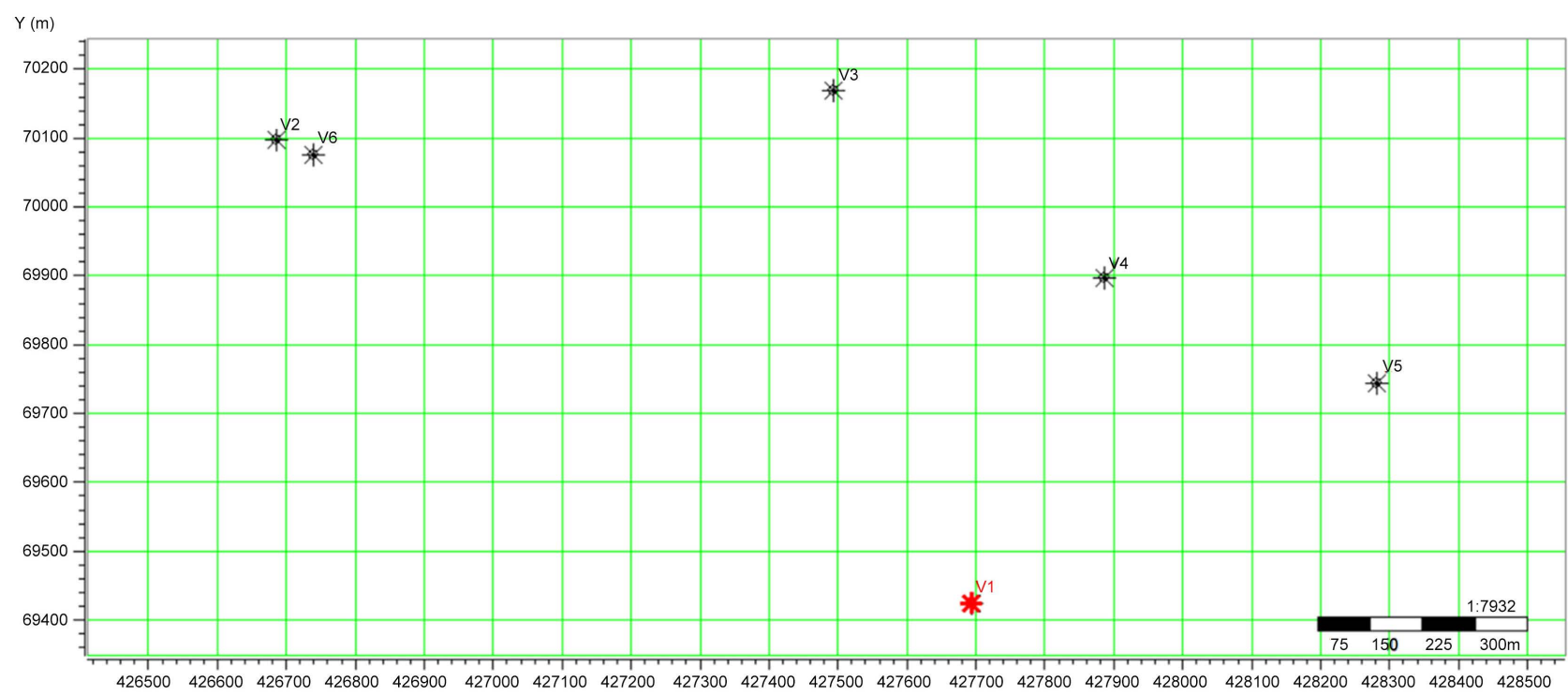

Figure 3. Base Map of VIA Field. 
Subsequently, the $V_{\text {sh }}$ of the mapped reservoir interval was evaluated for comparison using three computational strategies viz: linear and non-linear methods from GR log and the Neutron-Density method.

The first step in estimating $V_{\text {sh }}$ using the linear or non-linear GR method is to calculate the Gamma Ray Index (GRI) from the GR log [14] using Equation (1).

$$
\mathrm{GRI}=\frac{\mathrm{GR}-\mathrm{GR}_{\text {matrix }}}{\mathrm{GR}_{\text {shale }}-\mathrm{GR}_{\text {matrix }}}
$$

where,

GRI: Gamma Ray Index;

GR: Gamma Ray reading of log;

$\mathrm{GR}_{\text {matrix: }}$ Gamma Ray matrix-GR log reading in $100 \%$ matrix rock (or clean sand);

$\mathrm{GR}_{\text {shale: }}$ Gamma ray shale-GR log reading in $100 \%$ shale.

\subsection{GR Linear Method}

With this method the estimated $V_{\text {sh }}$ is proportional to the GRI [6] as defined in Equation (1). That is Equation (2),

$$
\left(V_{\text {sh }}\right)_{\text {Lin }}=\text { GRI }
$$

\subsection{GR Non-Linear (Larionov) Method}

The non-linear method used is the Larionov tertiary rocks method of estimating $V_{\mathrm{sh}}$ using the GR index from the GR $\log [9]$. This is given by Equation (3);

$$
\left(V_{\mathrm{sh}}\right)_{\mathrm{Lin}}=0.083 *\left(2^{(3.7 * \mathrm{GRI})}-1\right)
$$

\subsection{Neutron-Density Method}

The Neutron-density method uses Neutron and Density logs to estimate the $V_{\text {sh }}$ [15], using Equation (4).

$$
\left(V_{\mathrm{sh}}\right)_{\mathrm{ND}}=\frac{X_{1}-X_{0}}{X_{2}-X_{0}}
$$

where,

$$
\begin{gathered}
X_{0}=\mathrm{NPHI}_{\mathrm{MA}} \\
X_{1}=\mathrm{NPHI}+M_{1} *\left(\mathrm{RHOB}_{\mathrm{MA}}-\mathrm{RHOB}\right) \\
X_{2}=\mathrm{NPHI}_{\mathrm{Sh}}+\mathrm{M}_{1} *\left(\mathrm{RHOB}_{\mathrm{MA}}-\mathrm{RHOB}_{\mathrm{Sh}}\right) \\
M_{1}=\frac{\mathrm{NPHI}_{\mathrm{FL}}-\mathrm{NPHI}_{\mathrm{MA}}}{\mathrm{RHO}_{\mathrm{FL}}-\mathrm{RHOB}_{\mathrm{MA}}}
\end{gathered}
$$

with,

$$
\begin{aligned}
& \mathrm{NPHI}_{\mathrm{MA}} \text { : Neutron Porosity of Matrix; } \\
& \text { NPHI: Neutron Porosity at Log reading; } \\
& \mathrm{NPHI}_{\mathrm{Sh}} \text { : Neutron Porosity of Shale; } \\
& \mathrm{NPHI}_{\mathrm{FL}} \text { : Neutron Porosity of Pore Fluid; }
\end{aligned}
$$


RHOB $_{\mathrm{MA}}$ : Density of Matrix;

RHOB: Bulk Density at Log reading;

$\mathrm{RHOB}_{\text {Sh: }}$ : Density of Shale;

$\mathrm{RHO}_{\mathrm{FL}}$ : Density of Pore Fluid.

\section{Results Presentation}

Petrophysical analysis identified, mapped and correlated five (5) hydrocarbon reservoir sand intervals across the wells using GR, resistivity and combination of neutron-density logs. Each reservoir interval exhibits characteristic log signatures that are often related to the environment of deposition (EOD) and burial history. The mapped reservoir intervals varied in depths and thicknesses across wells (Figure 4), suggesting a structural control by faulting and uplifts, which is a major characteristic of the Niger Delta reservoirs [11]. For the purpose of this study, we focus on sand 4 reservoir interval for analysis based on petrophysical results (Table 2).

Table 2. Characteristic petrophysical properties of reservoir sand 4 .

\begin{tabular}{ccccc}
\hline Wells & Top $(\mathrm{m})$ & Base $(\mathrm{m})$ & Thickness $(\mathrm{m})$ & OWC (m) \\
\hline V1 & 3544 & 3680 & 136 & 3593 \\
V2 & 3555 & 3646 & 91 & - \\
V3 & 3535 & 3659 & 124 & 3614 \\
V4 & 3557 & 3659 & 102 & 3590 \\
V5 & 3557 & 3705 & 148 & 3613 \\
V6 & 3591 & 3691 & 100 & 3629 \\
& Average & & 117 & 3007 \\
\hline
\end{tabular}

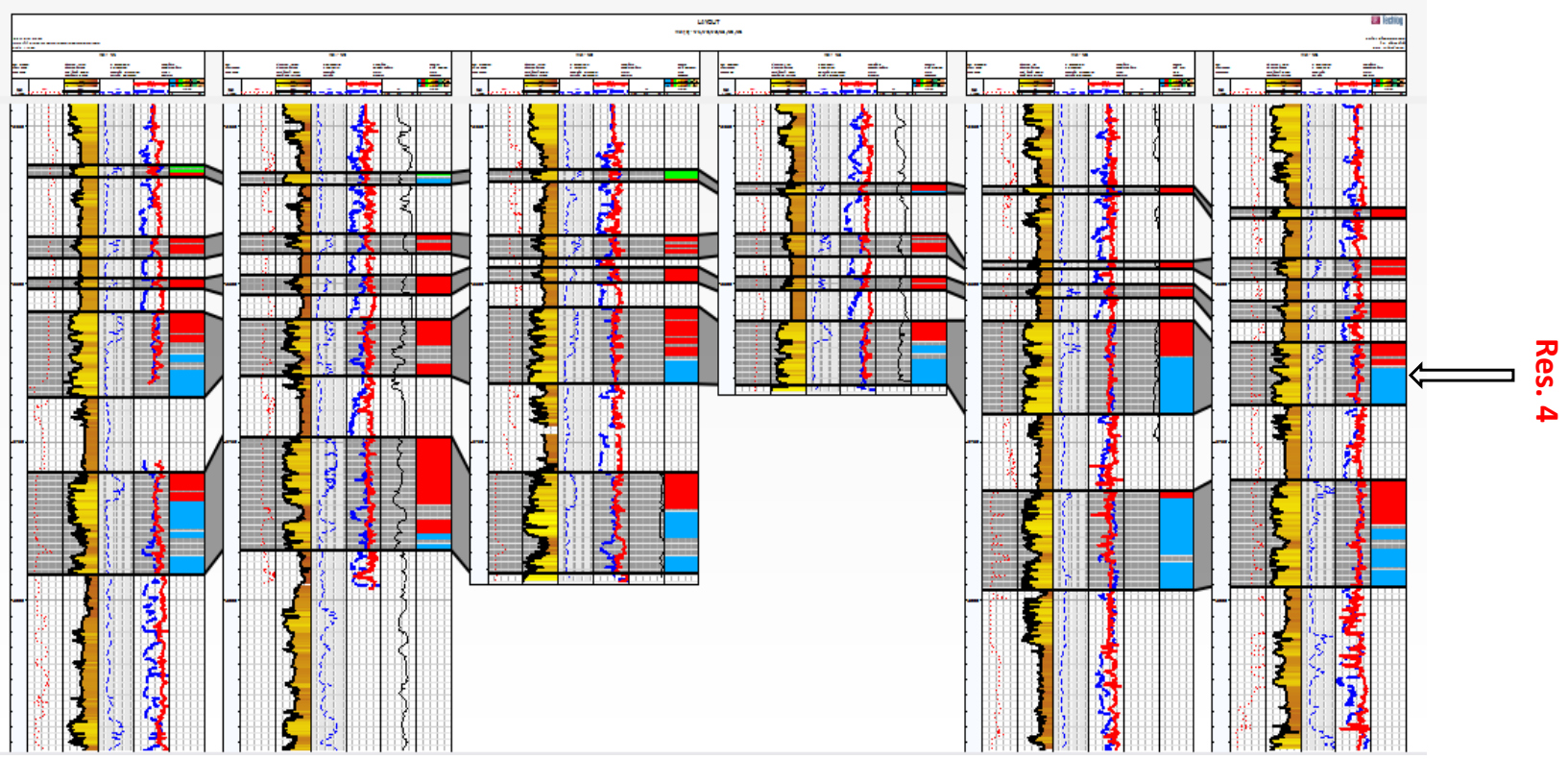

Figure 4. Well log correlation across the wells. 
The Potassium, Thorium and Uranium logs from well V5 in the field were plotted to evaluate radioactive materials other than shale in the reservoir interval. The plot shows non-specific and insignificant $\mathrm{K}$, Th and $\mathrm{U}$ radioactive content in the reservoir. Result suggests absence of radioactive materials such as feldspar in the reservoir (Figure 5). Furthermore, gas effect was evaluated by cross plotting neutron and density logs. Results show no significant ballooning or cross overs on the cross plots across wells, suggesting no or low gas content that could affect neutron-density analysis for $V_{\text {sh }}$ estimation (Figure 6).

The GR (linear and non-linear) and neutron-density methods were independently used to estimate $V_{\text {sh }}$ (Figure 6) and a plot of $V_{\text {sh }}$ vs. well was made for the reservoir interval across wells (Table 3 and Figure 7).

The $V_{\text {sh }}$ varies from $0.24-0.39,0.12-0.24$ and $0.04-0.28$ fractions for the GR linear, non-linear and neutron-density methods, respectively. This suggests very clean sandstones to deteriorated and clay-rich sandstones. The GR-linear method exhibits high $V_{\text {sh }}$ values than the non-linear (Larionov) method while neutron-density method is the least across wells. The $V_{\text {sh }}$ vs. well plots exhibit similar

Table 3. Average $V_{\text {sh }}$ computed from the different methods for reservoir sand 4 .

\begin{tabular}{cccc}
\hline Well & GR-Linear (Fraction) & GR-Larionov (Fraction) & Neutron-Density (Fraction) \\
\hline V1 & 0.29 & 0.14 & 0.09 \\
V2 & 0.39 & 0.24 & 0.28 \\
V3 & 0.33 & 0.16 & 0.07 \\
V4 & 0.24 & 0.12 & 0.07 \\
V5 & 0.25 & 0.14 & 0.04 \\
V6 & 0.38 & 0.21 & 0.07 \\
\hline
\end{tabular}

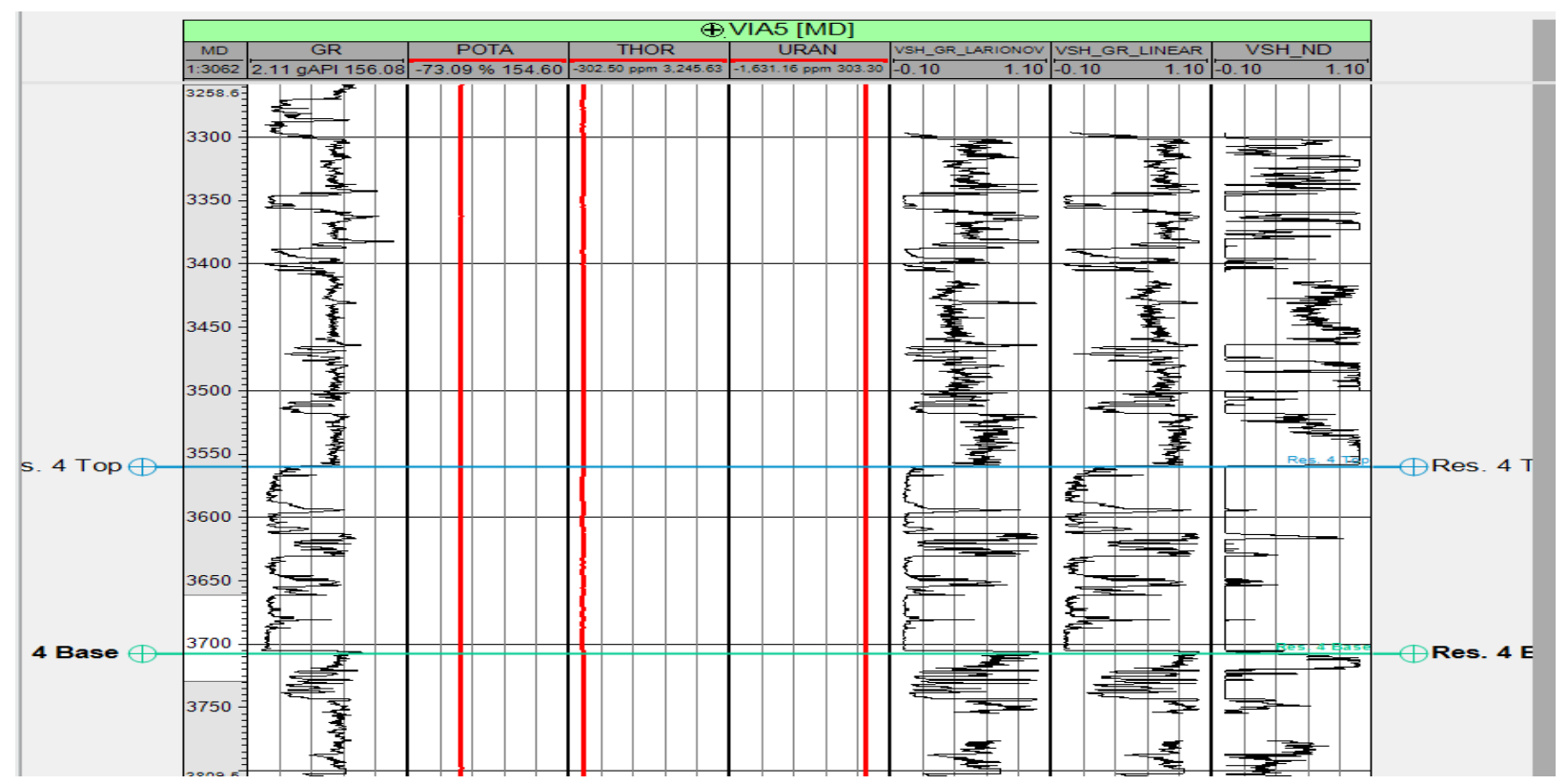

Figure 5. Plot of K, Th and U logs of Res. 4, Well 5. 

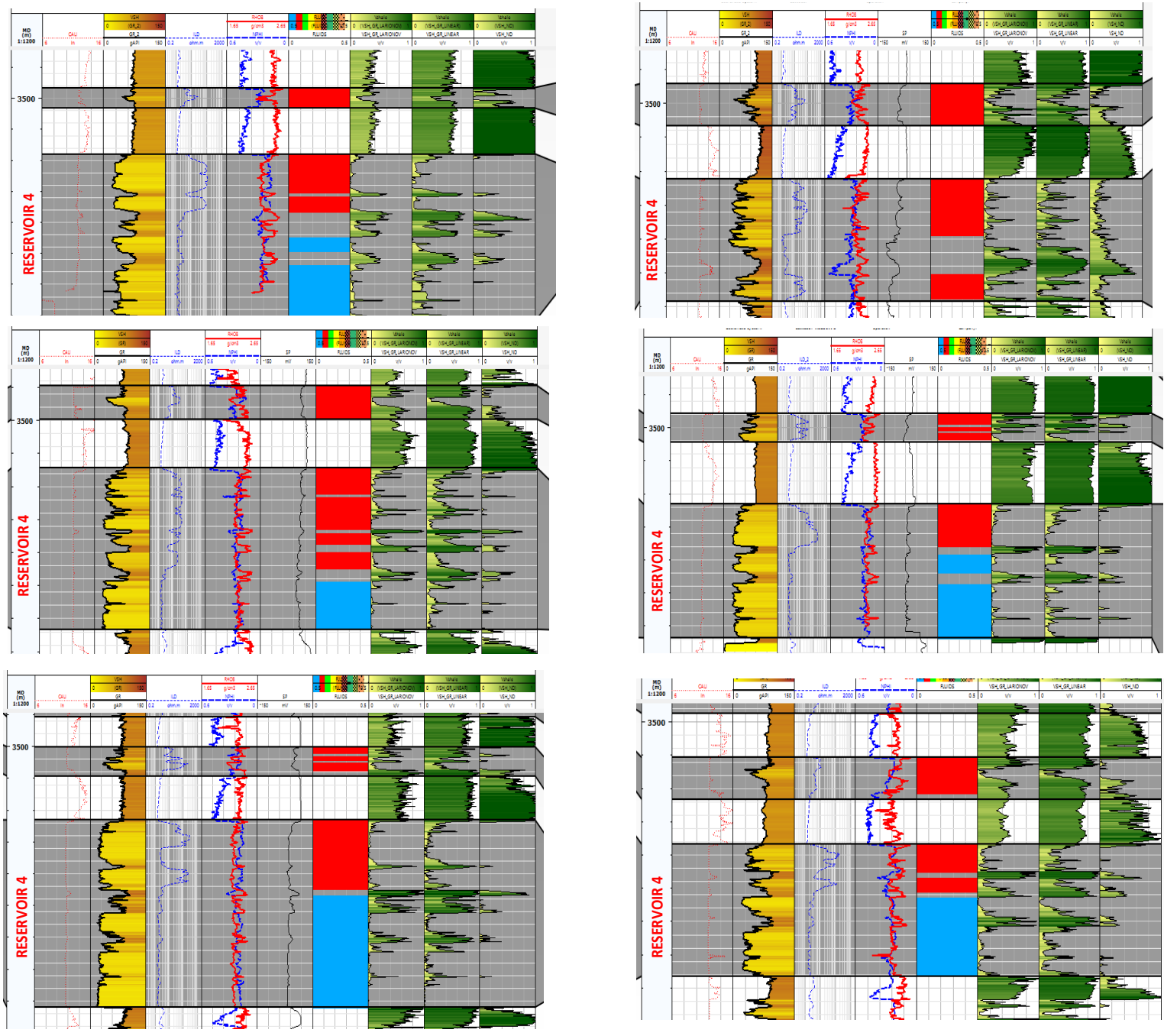

Figure 6. Estimated $V_{\mathrm{sh}}$ for sand 4 reservoir in each well from GR-linear and non-linear and ND methods, respectively.

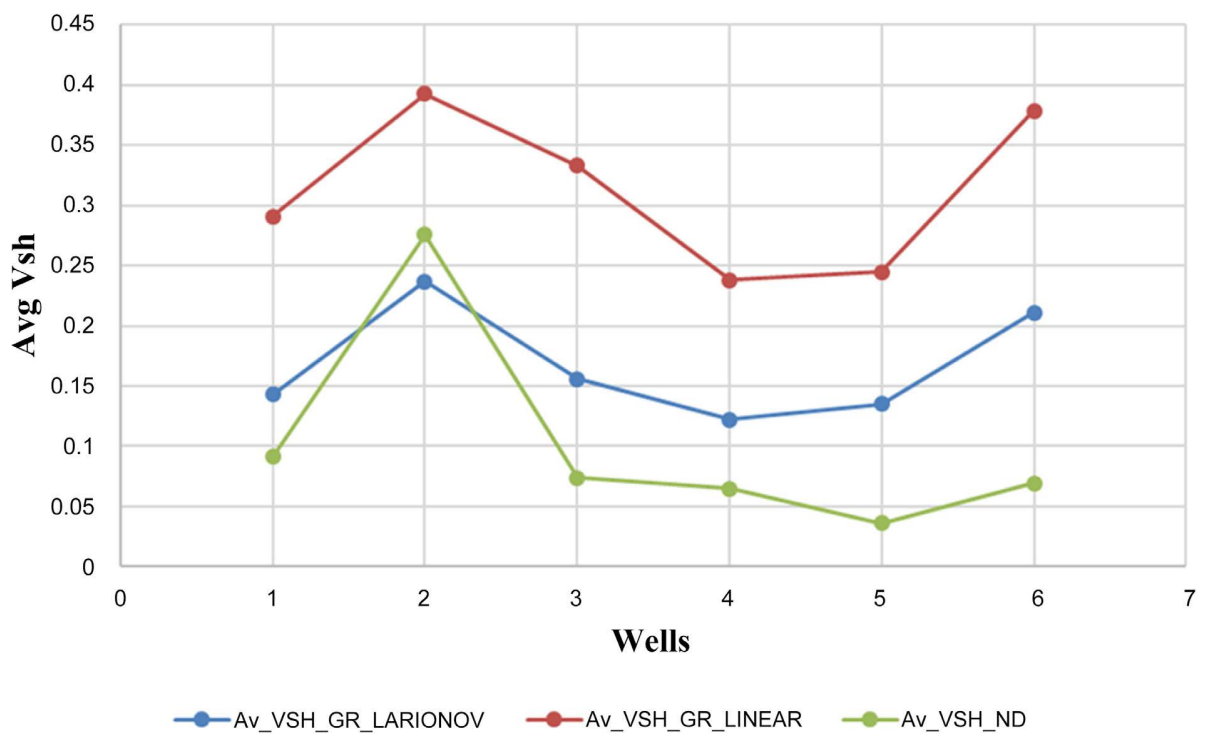

Figure 7. Plot of $V_{\text {sh }}$ vs. Well for Reservoir 4 interval using the different methods. 
data trends but different results for each of the methods across wells. GR methods estimate $V_{\text {sh }}$ values greater than the neutron-density method in the plot.

The exception to this is the high $V_{\text {sh }}$ of 0.28 fraction from the neutron-density method which is greater than the non-linear value of 0.24 fraction but lesser than 0.39 fraction of the linear method in well V2. This anomalous behaviour of the shale is likely to be due to post-depositional processes in well V2 reservoir interval as could be validated by the washout effect in the caliper log at the reservoir interval (Figure 6). Results show generally that well V2 has the highest $V_{\text {sh }}$ and well V5 the least for all the methods in the present study.

\section{Discussion of Results}

As expected in the Niger Delta region, wells V1 - V6 cut across intercalations of sandstones, shales and shaly sandstones. The reservoir intervals are generally heterogeneous with respect to lithology and microstructure which are strongly influenced by the environment of deposition and burial history. These affect matrix texture and quality and hence, the need to evaluate the reservoir properties for quantitative reservoir characterization.

The results of the present study show high $V_{\text {sh }}$ for GR-Linear and low for Neutron-Density method while GR-non linear is intermediate (Table 3 and Figure 7). According to [16], the linear method generally overestimates $V_{\text {sh. }}$ This is because in most cases, there exist a non-linear relationship between GR log response and $V_{\text {sh }}$ due to factors such as type of shale distribution, clay content and the possible presence of radioactive materials in the reservoir sands [6].

Reference [3], warns at having too low $V_{\text {sh }}$ with the Neutron-Density method, as this method depends on the condition of the well bore and presence of gaseous hydrocarbons. In our study, it was observed that neutron-density logs show no significant ballooning or cross overs on the cross plots across wells, suggesting no or low gas content that could affect $V_{\text {sh }}$ estimation. Furthermore, neutron $\log$ is more sensitive to shale content than the density log due to the high hydrogen index of shaly formations. The hydrogen index factor does not affect density log response. Therefore, the relative sensitivities of the logs to shale content, logging and wellbore complexities determine the accuracy and reliability of the neutron-density method in estimating $V_{\text {sh }}$.

The GR non-linear method (Larionov method) estimates intermediate $V_{\text {sh }}$ values in the reservoir interval across wells and provides consistent and comparable volume of shale estimations with the neutron-density method than the linear GR method. The GR methods may likely not be strongly influenced by logging and wellbore complexities due to singularity of measurement. Additionally, the absence of radioactive materials such as feldspar in the reservoir sands as shown in Th, $\mathrm{U}$ and $\mathrm{K}$ log plots makes the GR non-linear (Larionov) method even more appropriate for our study.

\section{Conclusion}

From the present analysis, the neutron-density method provides the lowest shale 
volume estimation for reservoir quality assessment than the GR methods. Due to logging sensitivities and wellbore complexities, reliable and full compliments of neutron-density logs measurements from the wellbore could be a daunting task. In such situations, using this method for shale volume estimation becomes problematic and unrealistic. However, the GR methods may likely not be strongly influenced by logging complications and wellbore conditions due to singularity of measurement. The GR non-linear (Larionov) method provides consistent and comparable volume of shale estimations with the neutron-density method than the linear GR method. Consequently, the non-linear GR method is recommended for estimation of $V_{\mathrm{sh}}$ in the studied field.

\section{Acknowledgements}

The authors are grateful to the World Bank, the Africa Centre of Excellence-Centre for Oilfield Chemicals Research (ACE-CEFOR) and the University of Port Harcourt. The first author will like to specially thank Mr. D. Fadokun, Prof. A. Noutcha, Dr. T. Dagogo and Dr. A. Balogun for their support.

\section{Conflicts of Interest}

The authors declare no conflicts of interest regarding the publication of this paper.

\section{References}

[1] Ejieh, E.O. and Ideozu, R.U. (2018) Effects of Shale Volume Distribution on the Elastic Properties of Reservoirs in Nan tin Field Offshore Niger Delta Nigeria. Journal of Applied Geology and Geophysics, 6, 68-85.

[2] Kamel, M.H. and Mabrouk, W.M. (2003) Estimation of Shale Volume Using a Combination of Three Porosity Logs. Journal of Petroleum Science and Engineering, 40, 145-157. https://doi.org/10.1016/S0920-4105(03)00120-7

[3] Kennedy, M. (2015) Practical Petrophysics. Vol. 62, Cubitt, J., Ed., Elsevier, Amsterdam.

[4] Pandey, A.K., Chatterjee, R. and Choudhury, B. (2020) Application of Neural Network Modelling for Classifying Hydrocarbon Bearing Zone, Water Bearing Zone and Shale with Estimation of Petrophysical Parameters in Cauvery Basin, India. Journal of Earth Systems Sciences, 129, Article No. 33. https://doi.org/10.1007/s12040-019-1285-4

[5] Ehsan, M. and Gu, H. (2020) An integrated Approach for the Identification of Lithofacies and Clay Mineralogy through Neuro-Fuzzy, Cross Plot, and Statistical Analyses, from Well Log Data. Journal of Earth Systems Science, 129, Article No. 101. https://doi.org/10.1007/s12040-020-1365-5

[6] Asquith, G. and Krygowski, D. (2004) Basic Well Log Analysis. Vol. 16, American Association of Petroleum Geologists, Tulsa, 31-34.

https://doi.org/10.1306/Mth16823

[7] Hamada, G.M. (1996) An Integrated Approach to Determine Shale Volume and Hydrocarbon Potential in Shaly Sand. Society of Core Analysts Conference, SCA Paper 9641.

[8] Mabrouk, W.M. and Kamel, M.H. (2011) Shale Volume Determination using Sonic, 
Density and Neutron Data. Exploration Geophysics, 42, 155-158.

[9] Doveton, J.H. (2014) Principles of Mathematical Petrophysics. Oxford University Press, New York. https://doi.org/10.1093/oso/9780199978045.001.0001

[10] Ejedawe, J.E. (1981) Patterns of Incidence of Oil Reserves in Niger Delta Basin. AAPG Bulletin, 65, 1574-1585. https://doi.org/10.1306/03B59620-16D1-11D7-8645000102C1865D

[11] Reijers, T.J., Petters, S.W. and Nwajide, C.S. (1997) The Niger Delta Basin. In: Selley, R.C., Ed., Sedimentary Basins of the World, Vol. 3, Elsevier, Amsterdam, 151-172. https://doi.org/10.1016/S1874-5997(97)80010-X

[12] Doust, H. and Omatsola, E. (1990) Niger Delta. In: Edwards, J.D. and Santogrossi, P.A., Eds., Divergent/ Passive Margin Basins, American Association of Petroleum Geologists, Tulsa, 239-248. https://doi.org/10.1306/M48508C4

[13] Rider, M. (1996) The Geological Interpretation of Well Logs. 2nd Edition, Rider-French Consulting Ltd., Sucherland.

[14] Asquith, G.B. and Gibson, C.R. (1982) Basic Well Log Analysis for Geologists. The American Association of Petroleum Geologists, Tulsa. https://doi.org/10.1306/Mth3425

[15] Paiva, M.F., Lupinacci, W.M., Freire, A.F. and Hansford, J. (2019) Comparison of Methodologies to Estimate the Clay Content-A Case Study in the Roncador Field, Campos Basin. Brazilian Geophysical Society, Rio De Janeiro.

[16] Soto, O.D., Soto, B.R., Soto, O.J., Pasquel, O. and Arteaga, D. (2015) A Universal Equation to Calculate Shale Volume for Shaly Sand and Carbonate Reservoirs. Society of Petroleum Engineers, Richardson. 